\title{
EFFICIENCY OF BUPROLORD AS INSECT GROWTH REGULATOR (IGR), ALONE AND IN A MIXTURE OF Ipomoea carnea Jacq. EXTRACT AGAINST SPIDER MITE, Tetranychus urticae Koch (Acari: Tetranychidae)
}

\author{
A. H. Mohana ${ }^{1}$; M.M.H. Kandeel ${ }^{1}$;.M. Eleawa ${ }^{2}$ and S.G. Saleh ${ }^{2}$. \\ (1) Faculty of Technology \& Development Zagazig University, Zagazig, Egypt. \\ (2) Plant Protection Research Institute, ARC, Dokki, Giza, Egypt.
}

\section{ABSTRACT}

The present study was conducted to evaluate the effect of buprolord as IGR against the two spotted spider mites (TSSM), Tetranychus urticae Koch. Also, the behavioristic action of mixture of buprolord and extract of Ipomoea carnea was included. A positive correlation between concentrations used and mortality percentages was recorded.

The idea was to try to reduce the extravagant of traditional pesticides. Buprolord was effective against T. urticae, protonymphs. When old eggs were treated with 250 ppm of the mixture kindly results were obtained. Mortality percentages were increased directly proportional with increasing concentration of buprolord. Old eggs of the mite, T. urticae were susceptible to the tested concentrations of buprolord during $72 \mathrm{hr}$. than in 24hr. where they were more sensitive. Concentration of $250 \mathrm{ppm}$ on T. urticae old eggs gave 26.06/female. On the other hand, the lowest concentration of 25 ppm gave 65.61 eggs compared with 65.35 eggs for the untreated females.

The IGR used here extended the developmental period to $T$. urticae by delaying the developmental rate.

Conclusively, The present study was conducted to evaluate the effect of buprolord as IGR against the two spotted spider mites (TSSM),Tetranychus urticae Koch. Buprolord was effective against T. urticae, protonymphs. Old eggs of the mite, T. urticae were susceptible to the tested concentrations of buprolord during $72 \mathrm{hr}$. than in $24 \mathrm{hr}$. The IGR used here extended the developmental period to T. urticae by delaying the developmental rate.

Keywords: Buprolord, I G. R., Ipomoea carnea, Extract, Tetranychus urticae.

\section{INTRODUCTION}

The two-spotted spider mite, $T$. urticae Koch is a major pest on field, glasshouse, horticultural, ornamental scrops and fruit trees (Van deVireet 
$a l ., 1972)$. It was considered one of the seriously sucking pests, feeds on more than 180 host plants causing damage in chlorophyll and produces white spots that eventually may become more or less coherent (Nachman \& Zemek, 2002 and Sim et al. 2003).

The ability of $T$. urticae to develop resistance to several acaricides has caused problems in many countries involved in agricultural production during the recent 40 years (Herron \&Rophail, 1998, Hinomoto \& Takafuji 1995 and Stumpf \& Nauen, 2001). The residual toxicity of the chemical neurotoxic insecticides on human and environment, control agents with comparative safety are searching by the entomologists. The systemic synthetic mimics of the insect hormones, which are best known as Insect Growth Regulators (IGRs) have been reported to be potent control agents against a number of pest insect of agriculture and fruit orchards (Fox, 1990). Among the IGRs, diflubenzuron and triflumuron are compounds which act as larvicides inhibiting larval molting; (Mulder and Gijswijt 1973) extend developmental time (Neumann and Guyer 1987) in different insect species. In addition, (Naher, et al. 2006) found that treating T. urticae with two IGRs, diflubenzuron and triflumuron significantly extended the duration periods of different developmental stages except deutonymph and adult. These compounds are non-toxic to non-target organisms.

Therefore, the present paper deals with the determination of the effects of buprolord $25 \%$ SC as anti-moulting on T. urticae immature stages and to study its effect as anti-moulting compound. Also, toxicological and biological aspects against $T$. urticae under laboratory conditions were recorded.

\section{MATERIALS AND METHODS}

\section{Two spotted spider mite, $T$. urticae rearing:}

A laboratory mite culture was initiated with 100 females and the same number of males collected from field. Population placed in rearing units or arenas (Helle and Overmeer 1985) in laboratory of Plant Protection Research Institute laboratory in Giza Governorate and maintained at $27 \pm 2^{\circ} \mathrm{C}$ and $70 \pm 10 \%$ RH. Males and females were transferred to Phaseolus vulgaris leaf disks in Petri- dishes (10 cm in diameter). They were kept for a period of $24 \mathrm{~h}$ to lay eggs. After this period, males and females were discarded and the eggs were reared until adult emergence.

\section{Tested compound}

Insect Growth Regulator (IGR)

Trade name: Buprolord 25\% SC

Common name: (Buprofezin). 
Chemical name: 2-tert-butylimino-3-isopropyl-5-phenyl-1,3,5-thiadiazinan-4-one.

Plant extract: Ipomoea carnea

\section{Buprolord 25\% SC assessment}

\section{Nymphacidal action}

The relative effect of pesticide, buprolord $25 \% \mathrm{SC}$ on mortality of phytophagous mite, $T$. urticae was assessed in tests with 80 protonymphs of T. urticae (8 replicate with 10 mites per replicate) the protonymphs at the same age of laboratory reared mite colony were individually transferred by the aid of a camel's hair brush to leaf discs. The bean leaf discs with mites were sprayed with different concentrations of an aqueous solution of buprolord 25\% SC, $(250,100,50$ and $25 \mathrm{ppm})$ that placed upper side down on moist cell cotton in Petri- dishes. Also, the same number of the protonymphs sprayed with distilled water was used as control, (Ebeling, 1960) technique. Mortality percentages of the individuals were evaluated at 24, 48 and $72 \mathrm{hrs}$. after treatment.

\section{Ovicidal action.}

The action of different concentrations of an aqueous solution of buprolord $25 \% \mathrm{SC},(250,100,50$ and $25 \mathrm{ppm})$ was carried out on eggs of $T$. urticae. Mated adult females were placed on mulberry leaf discs in Petridishes on moist cotton for 24 hrs. Thereafter, when a sufficient number of eggs were laid the adult females were removed. 80 newly deposited eggs at $24 \mathrm{hr}$ old age and 80 eggs at $72 \mathrm{hrs}$. The disc surface carrying the eggs at ages ranged between 24 and 72 hrs, were gently dipped separately in each concentration for about 5 seconds according to Ebeling, (1960). In control test, the leaf discs were dipped in distilled water only. The treated eggs as well as the control were kept under constant temperatures of $27 \pm 3^{\circ} \mathrm{C}$ and relative humidity of $65 \pm 5 \%$ R.H. In all cases, hatchability and mortality percentages were assessed.

\section{Latent effect of $L_{50}$ of buprolord $25 \%$ SC on longevity and fecundity of adult females obtained from treated nymphs:}

Eight adult mated females of $T$. urticae, were transferred to mulberry leave discs about $(1.5 \mathrm{~cm}$ diameter) and replicated 10 times. The leaf dipping technique was applied as mentioned above. Mortality percentages for individual were calculated the survive individual were observed then the duration and fecundity of individuals also calculated.

\section{Statistical analysis:}

Data were subjected to statistical analysis using one way analysis of variance, ANOVA Duncan (1955). 


\section{RESULTS AND DISCUSSION}

\section{Toxicological effect of buprolord $25 \% \mathrm{SC}$ against $T$. urticae nymphs:}

Table (1) cleared that there was positive correlation between concentrations and mortality percentages. Buprolord was effective against T.urticae, protonymphs. Mortality percentages were increased gradually, (after 1 day of treatment till 3 days), with increasing the concentration of antimolting, buprolord. After one day of treatment, the mortality percentages were $46.25,35.00,21.25$ and $15.00 \%$ for the successive concentrations $250,100,50$ and $25 \mathrm{ppm}$, respectively. While, the previous concentrations gave 87.5, 66.25, 47.50 and $32.50 \%$ accumulated mortality after 3 days for the previous same range. $\mathrm{LC}_{50}$ value after $72 \mathrm{hr}$. was $51.55 \mathrm{ppm}$. These results were nearly similar with (Abdel-Hafez, et al., 2014) that revealed the JHM; pyriproxyfen has contact toxicity against different developmental stages of $T$. urticae.

Table 1: Toxicity of buprolord $25 \% \mathrm{SC}$ against $T$. urticae protonymphs, during three time intervals.

\begin{tabular}{|c|c|c|c|c|c|}
\hline \multirow[t]{2}{*}{$\begin{array}{l}\text { Conc. } \\
\text { (ppm) }\end{array}$} & \multicolumn{3}{|c|}{$\begin{array}{l}\text { Mortality after time\% } \\
\text { post treatment (hours) }\end{array}$} & \multirow{2}{*}{$\begin{array}{c}\text { LC }_{50} \text { ppm } \\
\text { after } \\
72 \text { hrs. }\end{array}$} & \multirow[t]{2}{*}{ Slop } \\
\hline & 24 hr. & 48 hrs. & 72 hrs. & & \\
\hline 250 & 46.25 & 62.50 & 87.50 & \multirow{5}{*}{51.55} & \multirow{5}{*}{1.59} \\
\hline 100 & 35.00 & 50.00 & 66.25 & & \\
\hline 50 & 21.25 & 33.75 & 47.50 & & \\
\hline 25 & 15.00 & 27.50 & 32.50 & & \\
\hline Control & 1.25 & 1.25 & 2.50 & & \\
\hline
\end{tabular}

\section{Ovicidal action:}

The eggs of $T$. urticae were susceptible to the tested concentrations of buprolord after $72 \mathrm{hr}$., old eggs were more sensitive than 24hr. Table 2 and Figure 1 cleared that, $250 \mathrm{ppm}$ was the most effective concentration during 24 and $72 \mathrm{hrs}$. Old eggs of $T$. urticae where, $25 \mathrm{ppm}$ was the poorly effective of these concentrations. On the other hand, $\mathrm{LC}_{50}$ was 263.97 and $90.84 \mathrm{ppm}$ for 24 and $72 \mathrm{hrs}$. Old eggs of T. urticae. On one word the poorly effect of the compound was deleted with slope value. Low slope value conformed that individuals showed homogeneity to the lasted compounds (Hoskins\& Gordon, 1956). These results are agree with previous studies of El-Banhawy \& Amer (1992), which indicated that TSSM eggs were susceptible to the tested concentrations of flufenoxuron. At lower concentrations, the percentage of survival increased up to 96\% TSSM eggs (El-Banhawy and Reda, 1988) observed that dimilin, (anti-moulting) they lasted longer time to hatch and that effect was proportional to age of eggs of TSSM. 
Table 2: Ovicidal activity after treated with buprolord $25 \%$ SC against different ages of $T$. urticae, during different times intervals.

\begin{tabular}{|c|c|c|c|c|c|c|c|c|}
\hline \multirow[b]{2}{*}{$\begin{array}{l}\text { Conc. } \\
\text { (ppm) }\end{array}$} & \multicolumn{2}{|c|}{ 24hr.old eggs } & \multicolumn{2}{|c|}{72 hrs. old eggs } & \multicolumn{2}{|c|}{$\mathbf{L C}_{50}(\mathrm{ppm})$} & \multicolumn{2}{|c|}{ Slop } \\
\hline & $\begin{array}{c}\text { Mortality } \\
\%\end{array}$ & $\begin{array}{c}\text { Hatchability } \\
\%\end{array}$ & $\begin{array}{c}\text { Mortality } \\
\%\end{array}$ & $\begin{array}{c}\text { Hatchability } \\
\%\end{array}$ & $\begin{array}{c}24 \\
\text { hr. } \\
\text { old } \\
\text { eggs }\end{array}$ & $\begin{array}{c}72 \\
\text { hrs. } \\
\text { old } \\
\text { eggs }\end{array}$ & $\begin{array}{c}24 \\
\text { hr. } \\
\text { old } \\
\text { eggs }\end{array}$ & $\begin{array}{c}72 \\
\text { hr. } \\
\text { old } \\
\text { eggs }\end{array}$ \\
\hline 250 & 33.75 & 66.25 & 70.00 & 30.00 & \multirow{5}{*}{$\begin{array}{c}263 . \\
97\end{array}$} & \multirow{5}{*}{90.84} & \multirow{5}{*}{$\begin{array}{l}1.3 \\
1\end{array}$} & \multirow{5}{*}{1.76} \\
\hline 100 & 28.75 & 71.25 & 58.75 & 41.25 & & & & \\
\hline 50 & 15.00 & 85.00 & 37.50 & 62.50 & & & & \\
\hline 25 & 8.75 & 91.25 & 18.75 & 81.25 & & & & \\
\hline Control & 3.75 & 96.25 & 2.50 & 97.50 & & & & \\
\hline
\end{tabular}

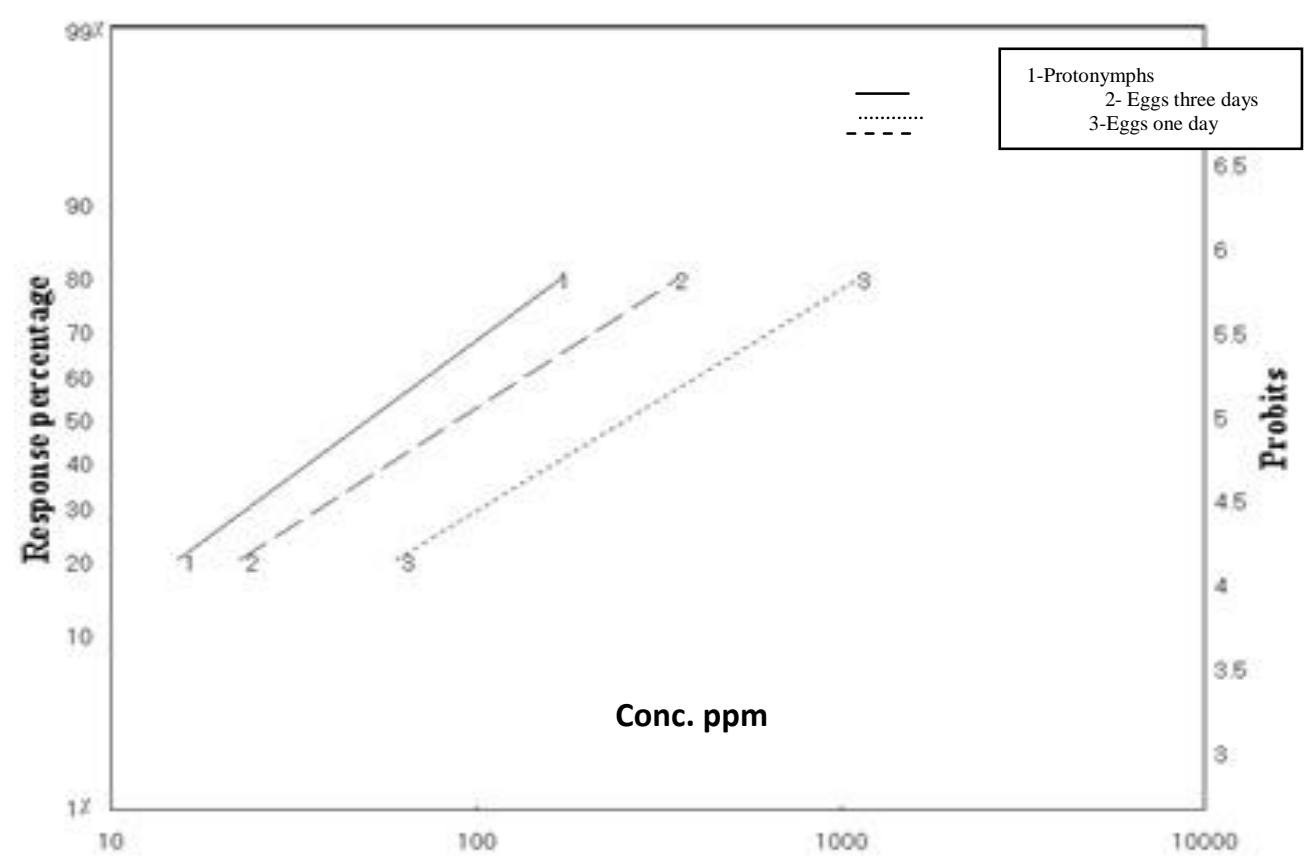

Figure 1: LC-P lines of buprolord 25\% SC on protonymphs and eggs of $T$. urticae.

Data in Table (3) showed that all concentrations of buprolord reducing the longevity and fecundity of adult females of $T$. urticae compared with control. The longevity decreased to 11.21 days in highest concentration while, in lowest concentration 25ppm was less than control (14.55\&20.42) days. The number of laid eggs was more decreased as concentration increased. The highest decrease in mean laid eggs was observed when the female treated 
Table 3: Effect of buprolord $25 \% \mathrm{SC}$ on some biological aspects of $T$. urticae.

\begin{tabular}{|c|c|c|c|c|c|}
\hline $\begin{array}{c}\text { Conc. } \\
(\mathbf{p p m})\end{array}$ & \multicolumn{3}{|c|}{ Duration (days) } & \multirow{2}{*}{ Longevity } & \multirow{2}{*}{ Fecundity } \\
\cline { 2 - 4 } & Pre-oviposition & Oviposition & Post-oviposition & & \\
\hline 250 & $3.62 \pm 0.13$ & $5.53 \pm 0.81$ & $2.06 \pm 0.96$ & $11.21 \pm .93^{\mathrm{c}}$ & $26.06 \pm 2.11^{\mathrm{d}}$ \\
\hline 100 & $2.91 \pm 0.09$ & $7.11 \pm 0.76$ & $3.25 \pm 0.76$ & $13.27 \pm 1.10^{\mathrm{b}}$ & $3841 \pm 2.41^{\mathrm{c}}$ \\
\hline 50 & $2.46 \pm 0.06$ & $9.12 \pm 0.96$ & $2.83 \pm 0.65$ & $14.41 \pm 1.33^{\mathrm{b}}$ & $50.34 \pm 2.18^{\mathrm{b}}$ \\
\hline 25 & $1.94 \pm 0.01$ & $10.29 \pm 1.23$ & $2.32 \pm 0.32$ & $14.55 \pm 1.2^{\mathrm{b}}$ & $65.61 \pm 3.72^{\mathrm{a}}$ \\
\hline Control & $1.50 \pm 0.09$ & $15.98 \pm 2.11$ & $2.94 \pm 0.18$ & $20.42 \pm 3.18^{\mathrm{a}}$ & $65.35 \pm 4.68^{\mathrm{a}}$ \\
\hline
\end{tabular}

Means in columns followed by the same letter are not significantly different at $0.05 \%$ level (Duncan's multiple range tests). \pm Standard Error

with concentration $250 \mathrm{ppm}$. It gives 26.06 eggs compared with 65.35 eggs for untreated female. Our results agree with (Rani and Mohan,1998 and Akashe, 2004) who indicated that treatment with IGR, flufenoxuron increased the duration periods of developmental stages and affected reproduction of $T$. urticae females.

Data in Table (4) showed that the plant extract of buprolord $25 \%$ SC when mixed with to produce mixture for each with 1:1 vivol. The joint action was its components more toxic than in a separately forms for $T$. urticae nymph $\mathrm{LC}_{\mathbf{5 0}}$ value of buprolord which mixed with $\mathrm{LC}_{\mathbf{5 0}}$ of plant extract after $72 \mathrm{hr}$. after treatment are causing mortality percentages were; $(97.50,75.00,55.00$ and 40.00$)$ for $250,100,50$ and $25 \mathrm{ppm}$, respectively. These results in harmony with those obtained by Waked, (2006) mixed plant extract, Fagoina arabica with vertimec against $T$. urticae.

Table 4: Toxicity of buprolord $25 \% \mathrm{SC}$ in mixed with $\mathrm{LC}_{50}$ of $I$. carnea extract against $T$. urticae during three times intervals.

\begin{tabular}{|c|c|c|c|c|c|}
\hline \multirow{2}{*}{$\begin{array}{c}\text { Conc. } \\
(\mathbf{p p m})\end{array}$} & \multicolumn{3}{|c|}{$\begin{array}{c}\text { Mortality after time \% } \\
\text { post treatment (hours) }\end{array}$} & \multirow{2}{*}{$\begin{array}{c}\text { LC } \\
\text { (ppm) }\end{array}$} & \multirow{2}{*}{ Slop } \\
\cline { 2 - 4 } & $24 \mathrm{hr}$. & $48 \mathrm{hrs}$. & $72 \mathrm{hrs}$. & & \\
\hline $\mathbf{2 5 0}$ & 52.50 & 70.00 & 97.50 & & \\
\hline $\mathbf{1 0 0}$ & 37.50 & 53.75 & 75.00 & \multirow{3}{*}{38.503} & \multirow{2}{*}{1.828} \\
\hline $\mathbf{5 0}$ & 30.00 & 43.75 & 55.00 & & \\
\hline $\mathbf{2 5}$ & 20.00 & 36.25 & 40.00 & & \\
\hline Control & 1.25 & 1.25 & 3.75 & & \\
\hline
\end{tabular}

Conclusively, The present study was conducted to evaluate the effect of buprolord as IGR against the two spotted spider mites (TSSM),Tetranychus urticae Koch. Buprolord was effective against $T$. urticae, protonymphs. Old eggs of the mite, T. urticae were susceptible to the 
tested concentrations of buprolord during $72 \mathrm{hr}$. than in $24 \mathrm{hr}$. . The IGR used here extended the developmental period to $T$. urticae by delaying the developmental rate.

\section{REFERENCES}

Abdel-Hafez, F. Hanan; A.M. Khalil and H.M. El-Nenaey (2014). Toxicological and biological effects of Juvenile Hormone Mimic (JHM) pyriproxyfen against the two spotted spider mite, Tetranychus urticae Koch (Acari: Tetranychidae). Acarines, 8(1):4953.

Akashe, V.B. (2004). Management of spotted spider mite, Tetranychus urticae Koch of rose during summer season. Journal of Maharashtra, Agri. Univ., 29 (1): 96-97.

Duncan, D.B. (1955). Multiple range and multiple F. tests. Biometrics, 11:1- 42.

Ebeling, W. (1960). Testing acaricides. In: Harold H. Shepard (ed.) Methods of testing chemical and chemicals and insects. Burges Publishing Co., Minneapolis., 11: 156-192.

El-Banhawy, E.M. and A.S. Reda (1988). Ovicidal effects of certain pesticides on the two-spotted spider mite, Tetranychus urticae and the predacious mite, Amblyseius gossipi (Acari: Tetranychidae: Phytoseii- dae). Insect Sci. Appl., 9: 369-372.

El-Banhawy, E.M. and S.A. Amer (1992). Retarded biology of the TSSM, T. urticae Koch after exposure to the anti-moulting compound, flufenoxuron under laboratory conditions. Appl. Entomol. Zool., 65(7): 126-128.

Fox, P. (1990). Insect Growth Regulators.PJB Publ. Ltd. Richmond, UK: 102 pp..

Helle, W. and W. Overmeer (1985). Toxicological test methods, In Helle W, Sabelis M. (eds.) Spider mites: their biology, natural enemies and control. Amsterdam, Elsevier Science Publishers B., 1: 391-395.

Herron, G.A. and J. Rophail (1998). Tebufenpyrad (pyranica) resistance detected in two-spotted spider mite, Tetranychus urticae Koch (Acari: Tetranychidae) from apples in western Australia. Exp. Appl. Acarol., 22:633-641.

Hinomoto, N. and A. Takafuji (1995). Genetic changes in the population structure of the two-spotted spider mite, Tetranychidae, on vinyl-house strawberries. Appl. Entomol. Zool., 30:521-528. 
Hoskins, W.K. and E.T. Gordon (1956). Arthropod resistance to chemicals. Ann. Rev. Entomol., :89- 122.

Mulder, R. and M.J. Gijswijt (1973). The laboratory evaluation of two promising new insecticides which interfere with cuticle deposition. Pestic. Sci., 4: 737-745.

Nachman G. and R. Zemek (2002). Interactions in a tritrophicacarine predator-prey etapopulation system III. Effects of Tetranychus urticae (Acari:Tetranychidae) on host plant condition. Ex. Appl. Acarol., 25:27-42.

Naher, N.; T. Islam; M.M. Haque and S. Parween (2006). Effects of native plants and IGRs on the development of T. urticae Koch (Acari: Tetranychidae). Journal of Zool., Rajshahi Univ., 25: 19-22.

Neumann, R. and W. Guyer (1987). Biochemical and toxicological difference in mode of action of the benzoylureas. Pestic. Sci., 20: 147-156.

Rani, B.J. and N.J. Mohan (1998). Cascade, a potential acaricide for management of two-spotted spider mite on rose. Insect. Environ., 4(1): 12-16.

Sim, C.; E. Seo and K. Cho (2003). Life table and sensitivity analysis as fitness evaluation method of fenpyroximate and pyridaben resistant two-soptted spider mite(Tetranychus urticae Koch). Journal of AsiaPacific Entomol., 6: 193-199.

Stumpf N. and R. Nauen (2001). Cross resistance, in heritance, and biochemistry of mitochondrial electron transport inhibitor-acaricide resistance in Tetranychus urticae (Acari:Tetranychidae). Journal of Economic, Entomology, 94:1577-1583.

Van de Vire M.; J.A. McMurtry and C.B. Huffaker (1972). Biology, ecology and pest status and host-plant relationships of tetranychids. Hilgardia, 41:343-432 .

Waked, A. Dalia (2006). Biological control evaluation of vegetables and fruits pests under the impact of natural extract. M.Sc. Thesis, Fac. Sci., Zagazig. Univ., :116 pp.. 
كفاءة البيبرولورد ه \% \% كمنظم نمو حشرى منفردا ومخلوطا مع

مستخلص نبات Ipomoea carnea ضد الحلم العنكبوتى urticae Koch (Acari: Tetranychidae)

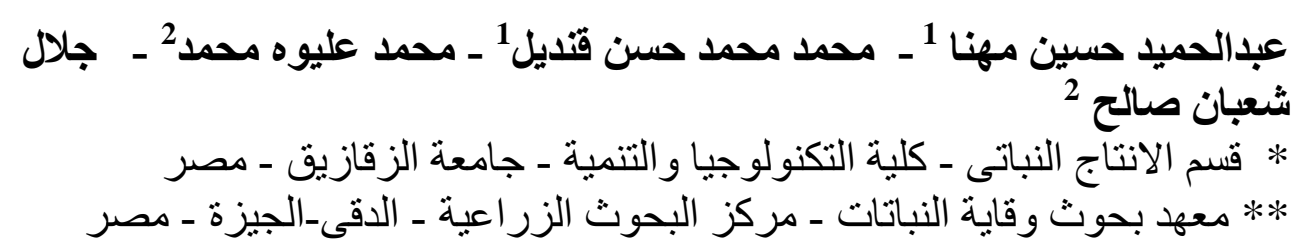

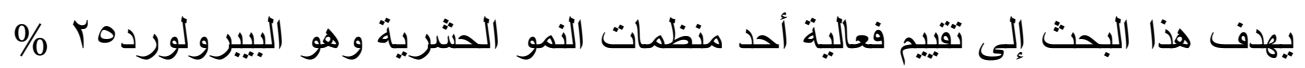

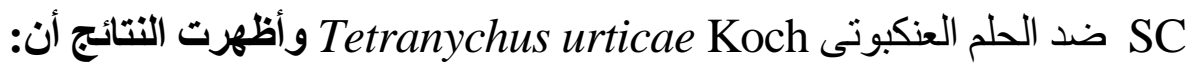

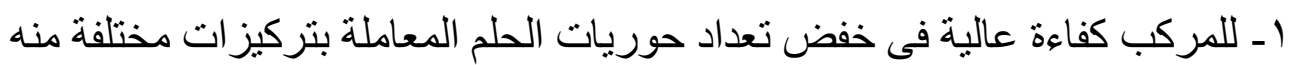

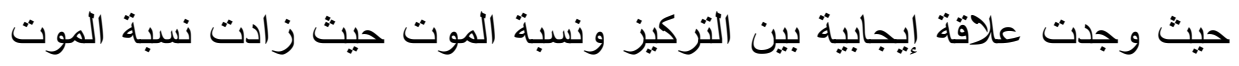

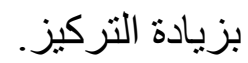

r- إستخدم منظم النمو ضد طور الترب البيضة عمر ثنلاث أيام وعمر يوم ووجد أن البيض

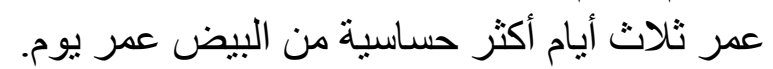

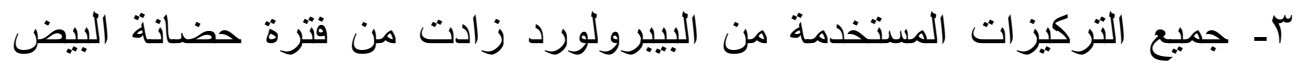

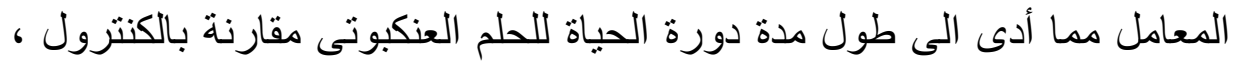

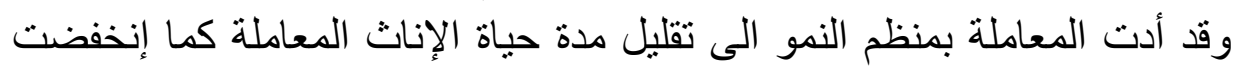

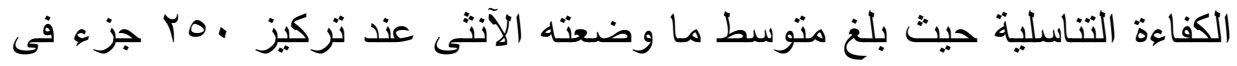

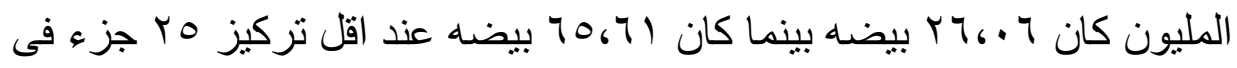

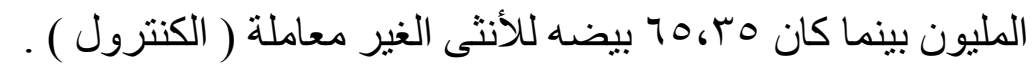

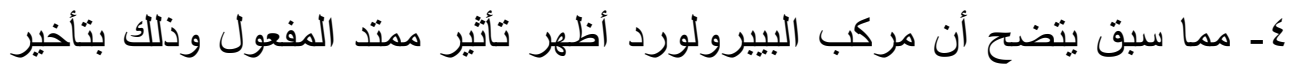

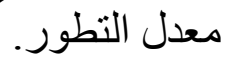

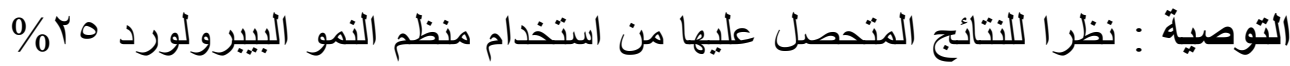

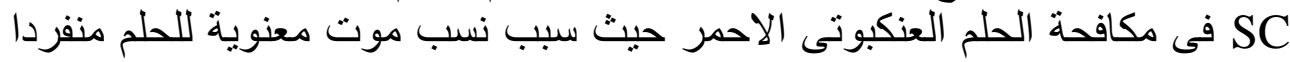

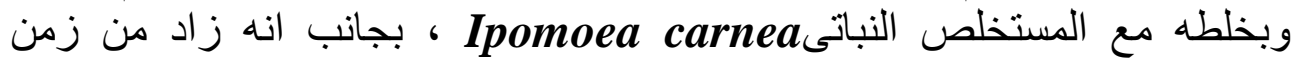

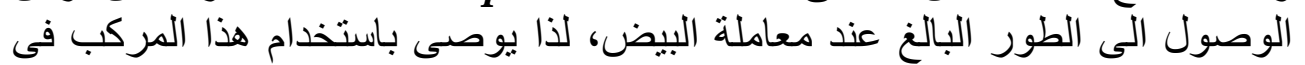
برامج المكافحة المتكاملة لهذه الافة. 